\title{
Evaluation of the performance of three elastomers for non-lethal projectile applications
}

\author{
N. Thota ${ }^{1,2, a}$, J. Epaarachchi ${ }^{2}$, and K.T. Lau ${ }^{2}$ \\ ${ }^{1}$ CAD-CAE Consultants, 45 Horley Tce, Kilburn, South Australia, 5084, Australia \\ ${ }^{2}$ Centre of Excellence in Engineered Fibre Composites, University of Southern Queensland, Toowoomba, 4350, \\ Queensland, Australia
}

\begin{abstract}
Less lethal kinetic ammunitions with soft noses such as eXact iMpact 1006, National Sports Spartan and B\&T have been commonly used by military and law enforcement officers in the situations where lethal force is not warranted. In order to explore new materials to be used as nose in such ammunitions, a scholastic study using finite element simulations has been carried out to evaluate the effectiveness of two rubber like elastomers and a polyolefinic foam (low density, highly compressible, stiff and closed cell type of thermos plastic elastomer). State-of-the art thorax surrogate MTHOTA has been employed for the evaluation of blunt thoracic trauma. Force-rigid wall method was employed for the evaluation of head damage curves for each material. XM 1006 has been used as the benchmark projectile for the purpose of comparison. Both blunt thoracic trauma and head damage criterion point of view, both rubbers (R1 and $\mathrm{R} 2$ ) have yielded high values of $\mathrm{VC}_{\max }$ and peak impact force. Polyolefinic foam (F1) considered in the study has yielded very promising $\mathrm{VC}_{\max }$ values and very less peak impact force when compared with those of bench mark projectile XM 1006.
\end{abstract}

\section{Introduction}

In the past few decades, law enforcement agencies, military and defense forces have started using less-lethal weapons which were designed to temporarily incapacitate the subject in the situations where lethal force is not warranted. The very basic requirement of non-lethal weapons are that the projectile impact should give short duration pain, be sufficient to deter the subject and should not cause any serious injuries, which require hospitalization and medical treatment [1-3].

Non-lethal munitions, though made up of foam and PVC, are very expensive (cost of each round of XM 1006 is approximately $30-55$ USD depending upon the order quantity $[4,5]$, and the cost of TASER-XREP round is more than 99 USD [6]). Therefore, a scholastic study was carried out to produce cheaper alternatives to XM 1006 which can be fired using the same M79 grenade launcher.

The projectile of interest XM 1006 (benchmark projectile in the present study), in the laboratory tests using 3-RCS, has produced a $\mathrm{VC}_{\max }$ of 0.21 at an impact velocity of $91.5 \mathrm{~m} / \mathrm{s}$. Though the design (dimensions) of the projectile is available in the technical documents published by Defense Tech, as there is no mention of the foam nose material data, the development of an XM 1006 equivalent foam nosed projectile becomes an arduous task and entails extensive physical tryouts with grenade launchers and thorax surrogates (Cadavers, surrogates, anesthetized animals) and experimental setup with costly equipment. Therefore, in the present study, authors have used a state of the art thorax surrogate MTHOTA

\footnotetext{
${ }^{a}$ Corresponding author: tnmurthy@cae-consultants . com.au
}

$[7,8]$ and experimentally obtained and validated material data of few elastomers (from the own database [9] and published articles by other researchers [10]) and validated 3 materials (Rubbers R1, R2 and Polyolefin F1) in a virtual testing environment whether or not they suitable as nose material in manufacturing less lethal ammunition.

Though XM 1006 is widely used and aerodynamically stable (spin stabilized), impacts on the head (due to dispersion effects) can be lethal as the peak impact force on the head at the speed of $60 \mathrm{~m} / \mathrm{s}$ is $>20 \mathrm{kN}$, which indicates very high probability for skull fracture and coma [11]. Therefore, in the present study, authors have employed force wall method and evaluated head damage characteristics of the projectile with R1, R2 and F1 noses.

In this paper, authors have presented blunt thoracic trauma and head damage characteristics of the projectile with R1, R2 and F1 noses and compared with those of the benchmark projectile.

\section{Methodology}

Non-linear finite element analyses were carried out for two purposes. Firstly, to evaluate the blunt thoracic trauma in terms of the peak viscous criterion and secondly, to evaluate head damage criterion in terms of peak impact force caused by the impacts of the projectiles with R1, R2 and F1 noses so that they can be compared with those of the benchmark projectiles XM 1006.

\subsection{Evaluation of the blunt thoracic trauma}

In order to evaluate the suitability of the materials under consideration as energy absorbing mechanisms

This is an Open Access article distributed under the terms of the Creative Commons Attribution License 4.0, which permits unrestricted use, distribution, and reproduction in any medium, provided the original work is properly cited. 


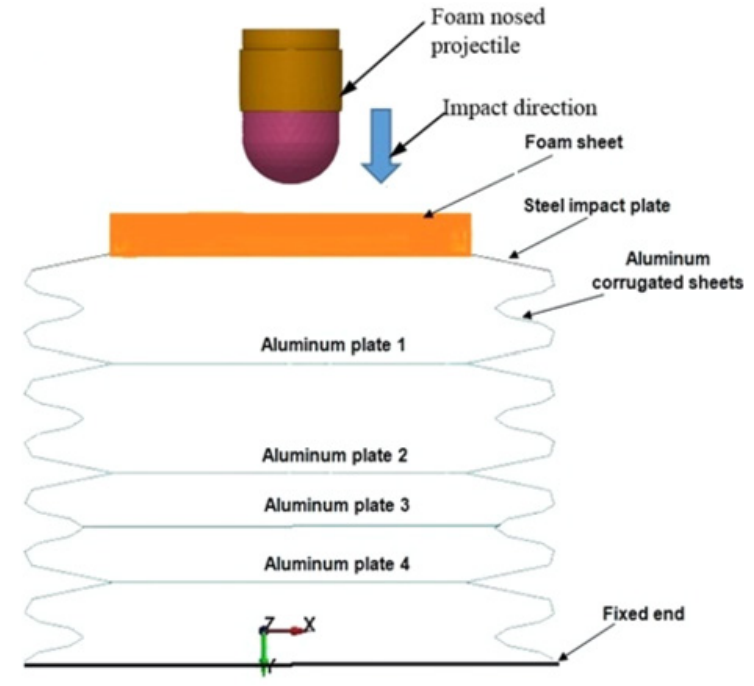

Figure 1. Details of MTHOTA thorax surrogate.

(compressible nose) in manufacture of non-lethal impact munitions, Mechanical THOrax for Trauma Assessment (MTHOTA), a state-of-the art surrogate of the thorax was subjected to the following cases impacts with projectiles whose design is similar to that of XM1006, in a virtual testing environment. Design details of the XM1006 were obtained from the published research papers and technical reports $[12,13]$.

1. An FEA non-linear simulation run with the projectile (nose made up of Rubber-1 material) impacting MTHOTA at $99 \mathrm{~m} / \mathrm{s}$ speed.

2. Repeat the above simulation run with Rubber-2 and Poly-olefin Foam as nose materials.

3. For better comparison, all of the above three cases were repeated with equivalent impact velocities. Equivalent velocities were evaluated such a way that initial kinetic energy of the projectiles were equal.

Construction details of the MTHOTA surrogate are illustrated in the Fig. 1.

MTHOTA surrogate is validated with human biomechanical response corridors developed by researchers at Wayne State University $[14,15]$ such a way that the peak viscous response $\left(\mathrm{VC}_{\max }\right)$ is given by the Eq. (1).

$$
V C_{\max }=S\left(Y_{\max } / D\right)\left(Y_{\max } / T\right)
$$

Where,

$\mathrm{VC}_{\max }=$ Peak viscous injury in $\mathrm{m} / \mathrm{s}$

$\mathrm{S}=$ Scaling factor $=0.366$ for MTHOTA

Ymax $=$ maximum deflection of the impact plate in $\mathrm{mm}$

$\mathrm{D}=$ Dummy constant $=110 \mathrm{~mm}$ for MTHOTA

$\mathrm{T}=$ time at which deflection is maximum in $\mathrm{ms}$.

Complete details of MTHOTA, its development, validation and its applications can be found in the research articles published by the present authors [7, 8, 16-18].
Table 1. Human head tolerance limits when subjected to blunt ballistic impacts [11].

\begin{tabular}{|c|c|}
\hline Type of head damage & Peak impact force (kN) \\
\hline Insignificant & $\leq 2.5$ \\
\hline Unconsciousness & $2.5 \leq$ peak impact force $\leq 5.0$ \\
\hline Meningeal & $5.0 \leq$ peak impact force $\leq 7.5$ \\
\hline Bone fracture and coma & $\geq 7.5$ \\
\hline
\end{tabular}

\subsection{Evaluation of head damage criterion by force wall method}

Due to dispersion effects, though most of the projectiles' designs are aerodynamically stable, there is a possibility of "subjects of interest" getting hit on the head. Such incidents can be fatal, if intracranial pressure caused by the impact is $\geq 150 \mathrm{kPa}$ which corresponds to $\geq 7.5 \mathrm{kN}$ peak impact force on the head. Table 1 delieneates relation between Peak impact force and the type of head damage, which was experimentally obtained by researchers of Direction Generale de l'Aremement (DGA) of the French Ministry of Defense.

The researchers at DGA have developed head damage curves for non-lethal ammunitions using both head and animal head biological models. The data was very well correlated with that obtained from the force wall method (impacting a perfectly rigid wall with the projectile). Oukura et al. [11] expressed the relation between peak impact force and impact velocity as given in the Eq. (1).

$$
(F)_{\text {Head }}=K *(V / 10)^{N} .
$$

Where,

$\mathrm{K}=$ experimetnally obtained coefficient

$\mathrm{N}=$ experimentallyobtained coefficient

$(F)_{\text {Head }}=$ Peak impact force on the head in $\mathrm{kN}$

$V=$ impact velocity of the projectile in $\mathrm{m} / \mathrm{s}$.

The following non-linear transient dynamic simulations were carried out for the evaluation of head damage criterion by force wall method.

1. Projectile with $\mathrm{R} 1$ nose impacting a rigid fixed plate at $20-100 \mathrm{~m} / \mathrm{s}$, with an increment of $10 \mathrm{~m} / \mathrm{s}$.

2. The above analyses were repeated with the projectile with $\mathrm{R} 2$ and $\mathrm{F} 1$ as nose materilas.

\subsection{Material data and material models used in the scholastic study}

Material properties and material models used for the FEA modelling of Rubbers (R1 and R2) and Polyolefin (F1) are given in the Table 2 and Table 3 respectively.

Engineering stress versus Engineering strain curve (as shown in the Fig. 2) obtained from the quasi static compression tests used in the modelling of MAT_057. In case of MAT_057 of LS-Dyna, a simple one term relaxation function (optional relaxation young's modulus) defines the rate effects of the material. Rate effects were ignored in the present study. In order to make the material model robust, some variables (HY, BETA, DAMP, etc., given in the Table 3) were obtaned by correlating the CAE simulations with rigourous experiments $[10,19]$. 
Table 2. Material properties and material data of Rubber-1 and Rubber-2.

\begin{tabular}{|c|c|c|}
\hline $\begin{array}{l}\text { Material } \\
\text { parameter }\end{array}$ & \multicolumn{2}{|l|}{ Details } \\
\hline Material model & \multicolumn{2}{|c|}{$\begin{array}{l}\text { MAT_MOONEY_RIVLIN_RUBBER } \\
\begin{array}{l}\text { (MAT_027 of } \\
\text { software) }\end{array}\end{array}$} \\
\hline $\begin{array}{l}\text { Strain energy } \\
\text { density } \\
\text { function }\end{array}$ & \multicolumn{2}{|c|}{$\begin{array}{l}\mathrm{W}=\mathrm{A}(\mathrm{I}-3)+\mathrm{B}(\mathrm{II}-3)+ \\
\mathrm{C}(\mathrm{III}-2-1)+\mathrm{D}(\mathrm{III}-1)^{2} \\
\mathrm{I}, \mathrm{II} \text { and III are invariants of right } \\
\text { Cauchy-Green Tensor } \\
\mathrm{C}=0.5 \mathrm{~A}+\mathrm{B} \\
\mathrm{D}=[\mathrm{A}(5 \mu-2)+\mathrm{B}(11 \mu-5)] / \\
(2-4 \mu)\end{array}$} \\
\hline $\begin{array}{l}\text { Shear modulus } \\
\text { of linear } \\
\text { elasticity }\end{array}$ & \multicolumn{2}{|c|}{$2(\mathrm{~A}+\mathrm{B})$} \\
\hline$\mu$ (Poisson's & \multicolumn{2}{|l|}{0.495} \\
\hline & Rubber-1 & Rubber-2 \\
\hline $\begin{array}{l}\rho \text { (mass } \\
\text { density) }\end{array}$ & $\begin{array}{l}1.07 \times \\
10^{-6} \mathrm{~kg} / \mathrm{mm}^{3}\end{array}$ & $0.97 \times 10^{-6}$ \\
\hline A & 0.0001243 & 0.000334 \\
\hline B & $6.14 \times 10^{-4}$ & 0.00167 \\
\hline
\end{tabular}

Table 3. Material data and material model of the polyolefin (Foam-1) used in the study.

\begin{tabular}{|l|c|}
\hline Polyolefin & Foam-1 \\
\hline Mass Density $\left(\mathrm{kg} / \mathrm{mm}^{3}\right.$ ) & $3.7 \times 10^{-8}$ \\
\hline Modulus of Elasticity (GPa) & 0.0105 \\
\hline Shape factor for unloading (SHAPE) & 15 \\
\hline Hysteretic unloading factor (HU) & 1.0 \\
\hline Decay constant (BETA) & 0.101 \\
\hline Viscous coefficient (DAMP) & 0.225 \\
\hline Material model (MAT_057) & MAT_LOW_- \\
& DENSITY_FOAM \\
\hline
\end{tabular}

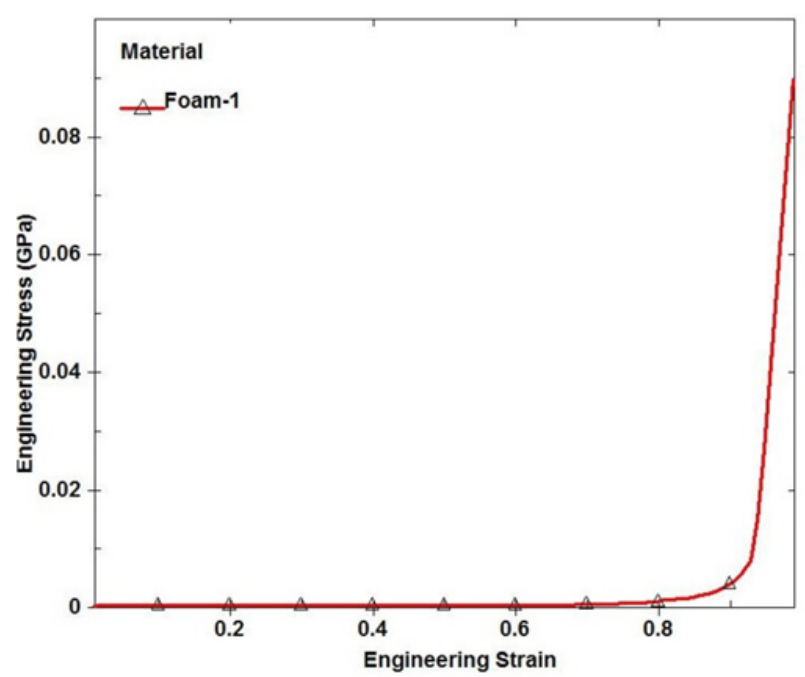

Figure 2. Stress-Strain curve for the Polyolefin Foam-1 material (obtained from the quasi-static compression test at $500 \mathrm{~mm} / \mathrm{min}$ strain rate.

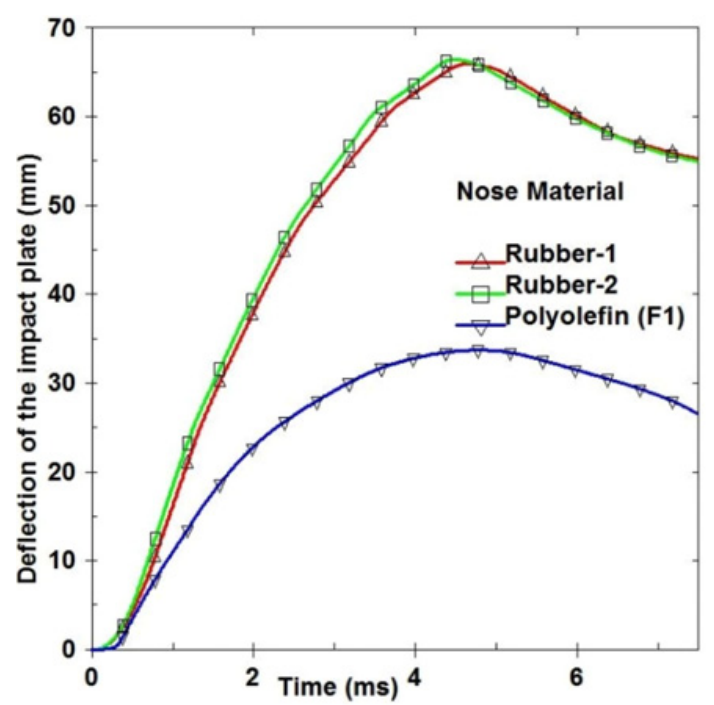

Figure 3. Dynamic deflection response of the MTHOTA when impacted at $99 \mathrm{~m} / \mathrm{s}$ impact speed.

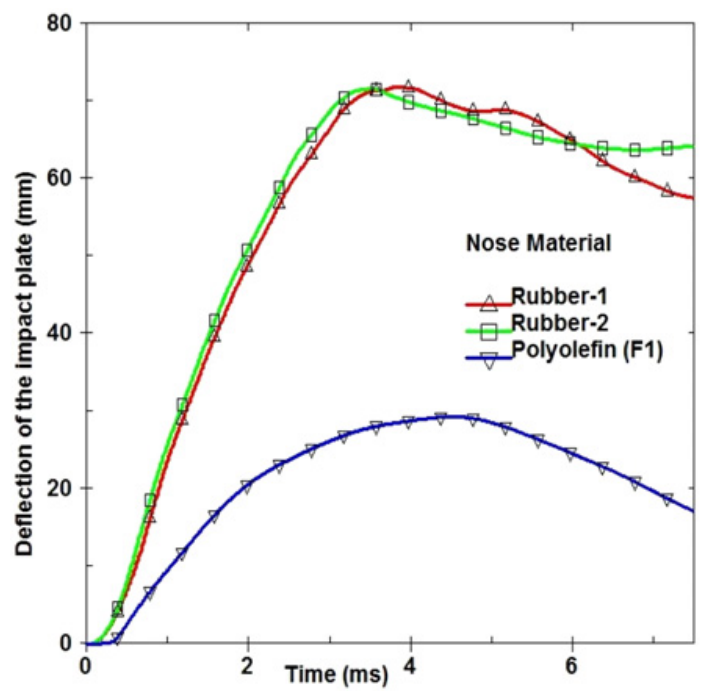

Figure 4. Dynamic deflection response of the MTHOTA when impacted with projectile with $147.03 \mathrm{~J}$ of initial Kinetic Energy.

\section{Results and discussion}

\subsection{Evaluation of the blunt thoracic trauma}

Blunt thoracic trauma in terms of $\mathrm{VC}_{\max }$ was evaluated for all impact cases ( 3 cases of projectile nose material and 2 cases of impact velocity) using the displacement time histories of the impact plate of the MTHOTA surrogate. Deflection-time responses of impact cases for are illustrated in the Fig. 3 and Fig. 4 Stages of MTHOTA and the projectile with polyolefin foam nose during the impact are shown in the Fig. 5.

Using the equation-1 and maximum deflection of the impact plate and impact duration at which deflection is maximum, $\mathrm{VC}_{\max }$ values were elicited for all projectile cases for impact speeds of $99 \mathrm{~m} / \mathrm{s}$ and equivalent speed and provided in the Table 4 and Table 5 respectively. 

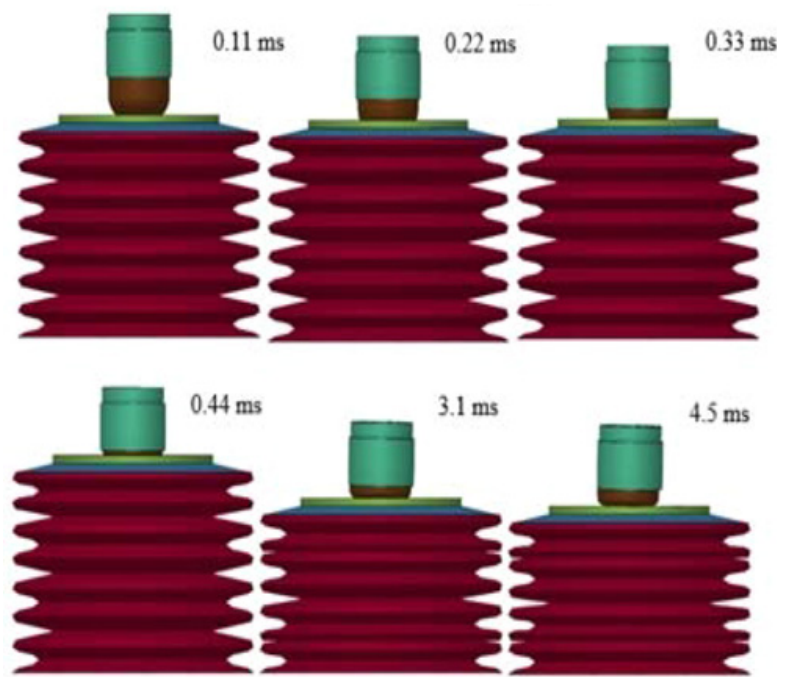

Figure 5. Stages of the MTHOTA when impacted with projectile with Polyolefinic nose at $99 \mathrm{~m} / \mathrm{s}$ impact speed.

Table 4. $\mathrm{VC}_{\max }$ values evaluated for $99 \mathrm{~m} / \mathrm{s}$ impact speed.

\begin{tabular}{|c|c|c|c|}
\hline $\begin{array}{c}\text { Nose } \\
\text { material }\end{array}$ & $\begin{array}{c}\text { Maximum } \\
\text { deflection }(\mathbf{m m})\end{array}$ & $\begin{array}{c}\text { Time } \\
(\mathbf{m s})\end{array}$ & $\begin{array}{c}\mathbf{V C}_{\mathbf{m a x}} \\
(\mathbf{m} / \mathbf{s})\end{array}$ \\
\hline Rubber-1 & 45.6 & 3.94 & 3.81 \\
\hline Rubber-2 & 44.8 & 3.29 & 4.41 \\
\hline Polyolefinic foam & 17.6 & 4.64 & 0.51 \\
\hline
\end{tabular}

Table 5. $\mathrm{VC}_{\max }$ values evaluated for equivalent impact speed.

\begin{tabular}{|c|c|c|c|}
\hline $\begin{array}{c}\text { Nose } \\
\text { material }\end{array}$ & $\begin{array}{c}\text { Maximum } \\
\text { deflection }(\mathbf{m m})\end{array}$ & $\begin{array}{c}\text { Time } \\
(\mathbf{m s})\end{array}$ & $\begin{array}{c}\mathbf{V C}_{\mathbf{m a x}} \\
(\mathbf{m} / \mathbf{s})\end{array}$ \\
\hline Rubber-1 & 39.5 & 4.38 & 2.57 \\
\hline Rubber-2 & 40.1 & 3.19 & 3.64 \\
\hline Polyolefinic foam & 19.1 & 4.74 & 0.71 \\
\hline
\end{tabular}

$\mathrm{VC}_{\max }=1.0 \mathrm{~m} / \mathrm{s}$ indicate that blunt thoracic trauma point of view the $25 \%$ probability for $\mathrm{AIS} 3+$ injuries. Both elastomeric rubbers have yielded very high $\mathrm{VC}_{\max }$ values and therefore, they are not suiable for making noses of the projectiles. Polyolefinic foam considered for the scholastic study has shown promising results as $\mathrm{VC}_{\max }$ values are very much less than the $1.0 \mathrm{~m} / \mathrm{s}$. It is important to note that at $99 \mathrm{~m} / \mathrm{s}$, benchmark projectile's $\mathrm{VC}_{\max }$ was evaluted as $0.21 \mathrm{~m} / \mathrm{s}$ using 3-RCS thorax surrogate. In order to evaluate at what impact speed, projectile with the polyolefinic foam nose would provide the similar viscous response, further simulations were carried out using the projectile with the polyolefinic foam nose with impact speeds of 70 and $75 \mathrm{~m} / \mathrm{s}$. $V_{\text {max }}$ values evaluated for these two impact cases were 0.25 and $0.31 \mathrm{~m} / \mathrm{s}$ respectively.

\subsection{Head damage criterion}

In the present study, non-linear finite element simulations were carried out by impacting a rigid fixed plate with the projectile with the softnose made up of Rubber-1. Impact speeds considered for this analysis were $20-100 \mathrm{~m} / \mathrm{s}$ (with an increments of $10 \mathrm{~m} / \mathrm{s}$ ). From the deceleration time histories of the projectile, peak impact forces were evaluated and illustrated in the Fig. 6.

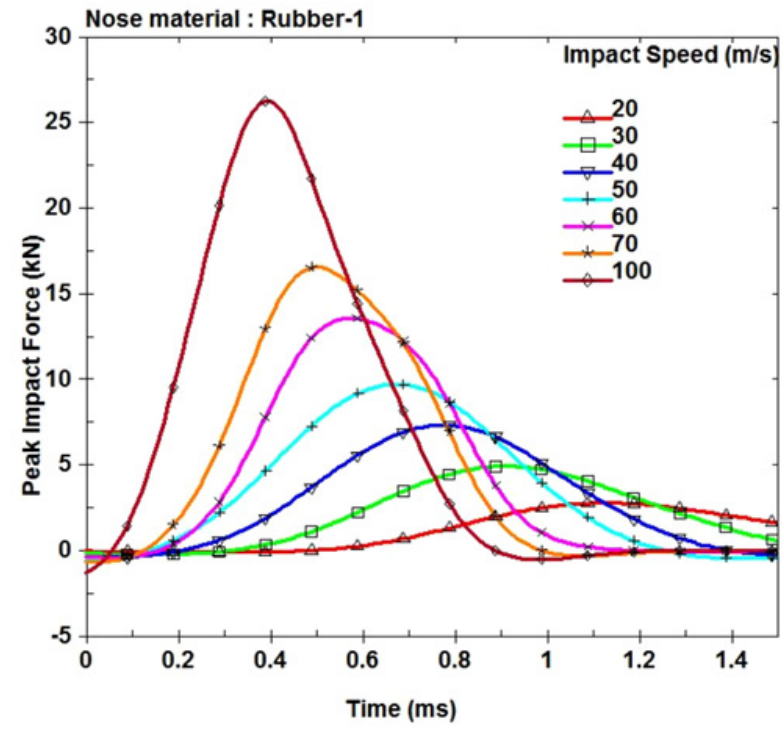

Figure 6. Force-time response of MTHOTA when impacted with the projectile with nose of Rubber-1.

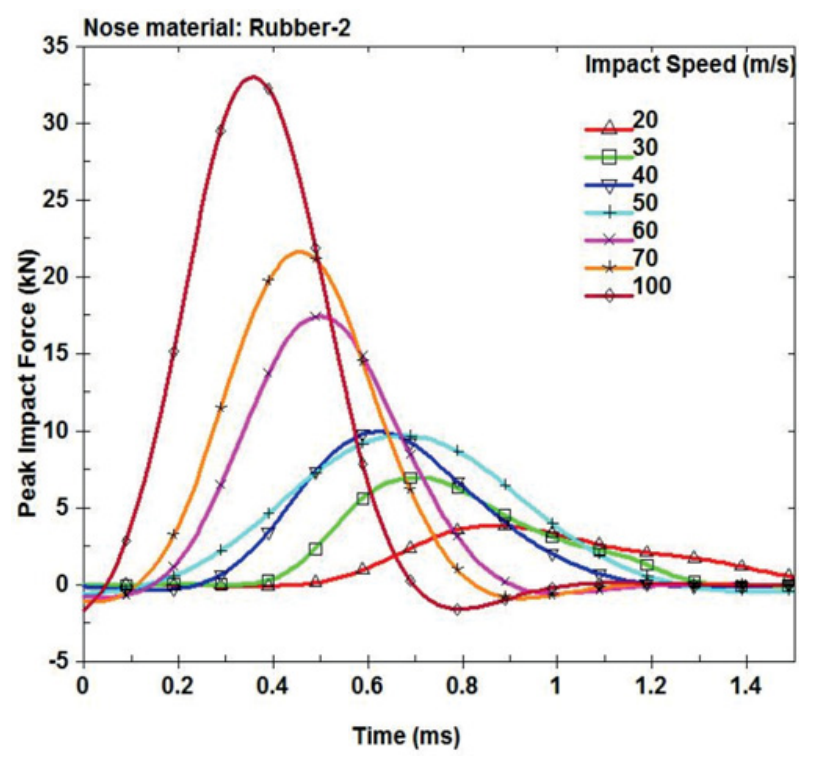

Figure 7. Force-time response of MTHOTA when impacted with the projectile with nose of Rubber-2.

Similar analyses were carried out for nose with materials Rubber-2 and Poly-olefinic foam. Force-time plots obtained from the analyses for these projectile cases are shown in the Fig. 7 and Fig. 8 respectively.

Head damage curves (peak impact force versus impact velocity) for all three cases of projectile (R1, R2 and F1 as nose materials), along with the bench projectile (XM 1006 as evaluated by Oukura et al. [11]) are illustrated in the Fig. 9.

From the Fig. 9, it is evident that the polyolefin Foam (F1) produced very promising results as at $60 \mathrm{~m} / \mathrm{s} \mathrm{impact}$ has yielded $7.35 \mathrm{kN}$ of peak impact force, when compared to the $20.12 \mathrm{kN}$ that is produced by the benchmark projectile. Projectiles with R1 and R2 noses also yielded 


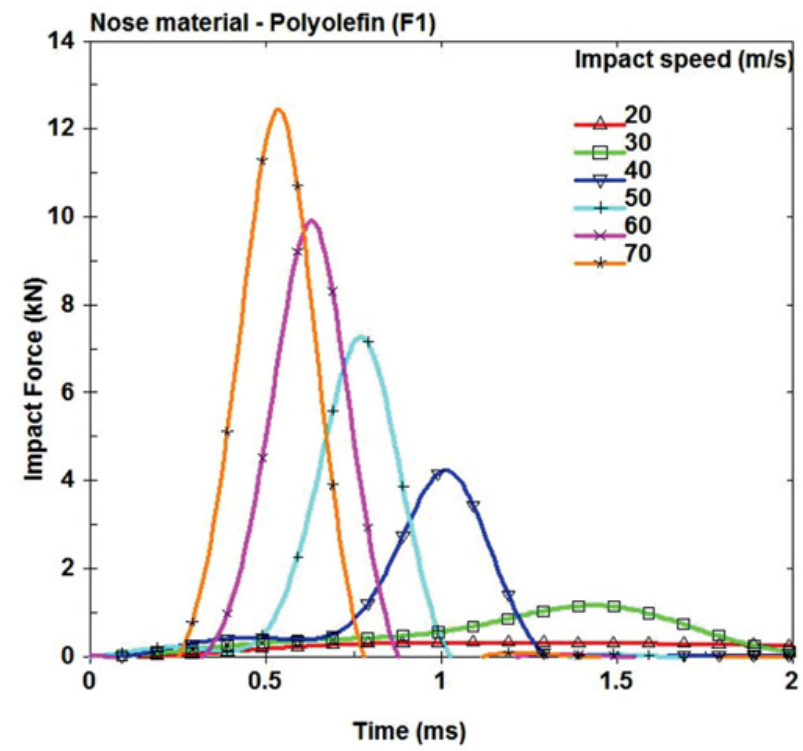

Figure 8. Force-time response of MTHOTA when impacted with the projectile with nose of Polyolefin foam (Foam-1).

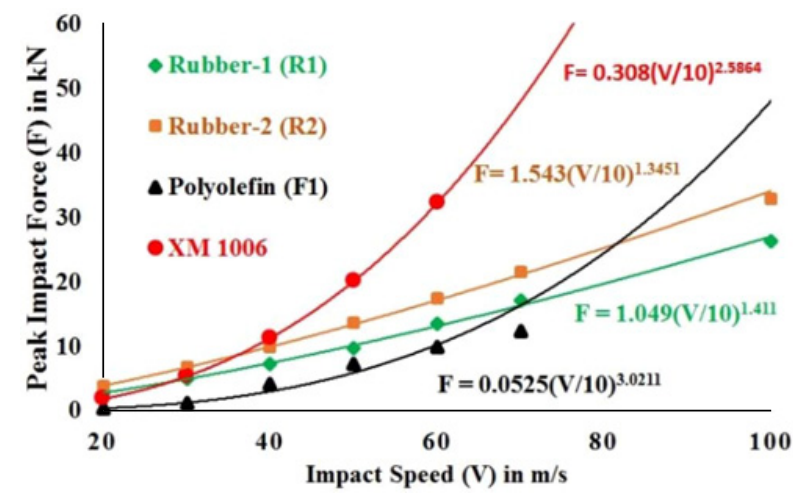

Figure 9. Head damage curves produced using force-wall method.

lesser peak impact forces than that of the benchmark projectile.

\section{Conclusions}

From the synthesis of the outcome of the FEA simulations, the following conclusions were drawn.

1. Projectiles with R1 and R2 noses have produced lesser peak impact forces on the head when compared to that produced by benchmark projectile. But, as far as the blunt thoracic trauama is concerned these projectiles have produced comparatively very high VCmax values, which disqualifies them as nose materials.

2. Projectile with polyolefin (F1) foam nose, as far as the head damage point of view, exibited better characteristics. Though the VCmax values produced by this projectile at $99 \mathrm{~m} / \mathrm{s}$ is $0.51 \mathrm{~m} / \mathrm{s}$ which is more than that of the benchmark projectile, the results are very promising.
3. Projectile with polyolefin foam (F1) has produced VCmax value of $0.25 \mathrm{~m} / \mathrm{s}$ and peak impact force $12.2 \mathrm{kN}$. Blunt thoracic trauma point of view, at this impact speed, the projectile with F1 nose produced almost an equal effect and head trauma point view, the peak impact force was reduced by $75 \%$ when compared with those of the benchmark projectile.

The principal author gratefully acknowledges Mr Velizar Sedev and Mr Jason Tamas, Directors of CAECON of Adelaide of South Australia for complete sponsorship to attend the DYMAT-2015 conference. He also thanks Mr Srinivasa Rao Koya, Chairman of Amerigo Structural Engineers Private Limited, Bangalore, India' for providing the necessary funds and resources for the successful completion of the research project.

\section{References}

[1] J. Widder, C. Perhala, and J. Rascoe, "Caseless, Variable Velocity Systems for Precision Non-Lethal Fires to beyond 100 Meters. Part-II: Terminal effects Study, Selection of Projectile Parameters," AMMTIAC-WSTIAC Journal vol. 1, pp. 13-16 (2003).

[2] J.M. Widder, D.J. Butz, and J.M. Milosh, "Assessing the Blunt Trauma Potential of Free Flying Projectiles for Development and Safety Certification of NonLethal Impactors," Battelle Columbus Operations, Columbus, OH 43201, USA (1997).

[3] B. Koene, F. Id-Boufker, and A. Papy, "Kinetic non-lethal weapons," Netherlands annual review of military studies, pp. 9-24 (2008).

[4] (2011, 15/02/2015). X1006 Sponge Round (Point), http://www.globalsecurity.org/military/ systems/munitions/40-nl.htm

[5] (2015, 15/02/2015). Defnse Technology eXact iMpact Sponge Round, $40 \mathrm{~mm}$ [Electronic]. Available: http: //www . chief supply. com/defensetechnology-exact-impact-sponge-round$40 \mathrm{~mm} \cdot \mathrm{html}$

[6] S. Johnson. (2010, February 1, 2015). Taser XREP Up Close (and pricing!). TFB - The Firearms Blog. Available: http://www.thefirearmblog . com/blog/2010/02/10/taser-xrep-up-closeand-pricing/

[7] N.M. Thota, J.A. Eepaarachchi, and K.T. Lau, "Develop and validate a biomechanical surrogate of the human thorax using corrugated sheets: a feasibility study," in Proceedings of the 7th Australasian Congress on Applied Mechanics (ACAM 7), (2012).

[8] N. Thota, J. Epaarachchi, and K.T. Lau, "Development and validation of a thorax surrogate $\mathrm{FE}$ model for assessment of trauma due to high speed blunt impacts," Journal of Biomechanical Science and Engineering, vol. 9, pp. JBSE0008-JBSE0008 (2014).

[9] N. Thota, "Development and Validation of a Mechanical Thorax Surrogate for the Evaluation of the Blunt Trauma Due to Ballistic Impacts" Doctor of Engineering, Centre of Excellence in Engineered 
Fibre Composites, University of Southern Queensland, Australia (To be published).

[10] G. Slik, G. Vogel, V. Chawda, and D. Automotive, "Material model validation of a high efficient energy absorbing foam," in Proceedings of the 5th LS-DYNA Forum (2006).

[11] A. Oukura, C. Robbe, N. Nsiampa, and A. Papy, "Comparison of the lethality of different kinetic energy non-lethal projectiles using a new French assessment approach for head impacts," presented at the 27th International symposium on ballistics Freiburg, Germany (2013).

[12] D.H. Lyon, "Development of a $40 \mathrm{~mm}$ nonlethal catridge," Defense Technology Federal Laboratories Research Journal, pp. 64-78 (1997).

[13] D.H. Lyon, C.A. Bir, and B.J. Patton, "Injury Evaluation Techniques for Non-Lethal Kinetic Energy Munitions," DTIC Document (1999).

[14] C. Bir, D. Viano, and A. King, "Development of biomechanical response corridors of the thorax to blunt ballistic impacts," J Biomech, vol. 37, pp. 73-9 Jan. (2004).

[15] C.A. Bir, "The evaluation of blunt ballistic impacts of the thorax," Doctor of Philosophy, Biomedical Engineering, Wayne State University, Detroit, Michigan, USA (2000).
[16] N.M. Thota, J.A. Eepaarachchi, and K.T. Lau, "Effect of energy absorbing mechanisms on the blunt thoracic trauma caused by ballistic impacts," in Proceedings of the 8th Australasian Congress on Applied Mechanics (ACAM 8), Melbourne Convention Centre, Melbourne, Victoria, Australia (2014).

[17] N.M. Thota, J.A. Eepaarachchi, and K.T. Lau, "Evaluation of the blunt thoracic trauma due to baseball impacts - Review of the blunt criterion," in Proceedings of the 8th Australasian Congress on Applied Mechanics (ACAM 8), Melbourne Convention Centre, Melbourne, Victoria, Australia (2014).

[18] N.M. Thota, J.A. Eepaarachchi, and K.T. Lau, "Viscous criterion and its relation with the projectilethorax energy interactions," in Proceedings of the 8th Australasian Congress on Applied Mechanics (ACAM 8), Melbourne Convention Centre, Melbourne, Victoria, Australia (2014).

[19] F. Pan, S. Quander, and Z. Ma, "Use of material models for elastomer foams in ABAQUS and LS-DYNA," in Constitutive Models for Rubber IV - Austrell \& Kari (eds). vol. IV, A. Kari, Ed., ed London: Taylor \& Francis Group, 2005, pp. 593-597. 